\title{
Natural resources and the spread of HIV/AIDS: curse or blessing?
}

\begin{abstract}
This paper answers two questions: "What impact have natural resources had on the spread of the HIV epidemic so far?" and "What role can natural resource rents play in order to finance the long-run response to HIV/AIDS?" Using a panel dataset covering 137 countries from 1990 until 2008, de Soysa and Gizelis (2013) provided evidence in Social Science $\&$ Medicine that oilrich countries are more deeply affected by the HIV and TB epidemics. They concluded that government of resource-rich countries failed to implement effective public policies for dealing with the epidemics. In this paper, I show that their results are (1) not robust, (2) based on an inappropriate choice of dependent variable and (3) spurious because series are non-stationary. After correcting for these issues, I find no robust relationship between resource rents and the spread of HIV and TB. The paper concludes by emphasizing the potential of natural resources rents for financing the long-term liability brought about by the HIV/AIDS epidemic in sub-Saharan Africa.
\end{abstract}

Keywords: HIV/AIDS, natural resources, resource curse, epidemics, spurious regression, non-stationarity 


\section{Introduction}

Since the 2008 financial turmoil, international HIV assistance stagnated and AIDS expenditures remain short of the global target of US\$22-24 billion in annual financial resources (UNAIDS, 2013a). Given the stagnation in international funding, high-prevalence countries will have to increase their own contribution to the fight against HIV/AIDS. Within this context, the abundance of natural resources in sub-Saharan Africa may seem a panacea. However, in a recent paper, de Soysa and Gizelis (2013) (hereafter DG) showed that oil wealth is associated with a higher prevalence rate of HIV, higher death rates from AIDS and a higher prevalence of tuberculosis (TB). The authors interpret their findings by referring to the large and heavily debated literature on the resource curse (van der Ploeg, 2011). In particular, they suggest that the "resource curse affects the spread of diseases because of the effect on rulers' incentives, as rulers in resource-wealthy states are more likely to neglect public goods provision, such as health, and neglect effective public action".

In line with the analysis of DG, this paper aims to answer two intermingled questions: "Have natural resource rents had an impact on the spread of the HIV/AIDS and TB epidemics so far?" and "What role can natural resource rents play in order to finance the long-run response to HIV/AIDS in sub-Saharan Africa?" The analysis proceeds in three steps. First, I argue that the empirical analysis of DG suffers from problems which cast doubts on the existence of a resource curse on HIV/AIDS. I show that the positive association between oil rents and the spread of the HIV and TB epidemics is spurious because the dependent variables (HIV prevalence, death rate from 
AIDS and TB prevalence) and explanatory variables (oil rents per capita) are non-stationary. I argue that the expected impact of good public action on HIV prevalence is ambiguous in the short run, which makes the results of DG impossible to interpret. Death rates from AIDS and TB prevalence are affected by similar problems. In a second step, I use different empirical methods to correct these flaws and find no specific relationship between oil rents and the spread of HIV/AIDS. Finally, I discuss the potential of natural resource rents for financing the long-term liability brought about by the scaling-up of ART in sub-Saharan Africa. In particular, the analysis identifies countries where an efficient management of natural resource rents could provide the necessary fiscal space for scaling-up ART coverage in the future.

\section{Revisiting de Soysa and Gizelis (2013)}

The objective of DG was to assess the impact of resource abundance on the spread of epidemics. Their analysis considered three dependent variables: the logarithm of HIV prevalence, the logarithm of the death rate from AIDS, and the logarithm of TB prevalence. The main explanatory variable is the oil rents per capita in current US\$ from the World Bank environmental accounting indicators. The control variables considered are the logarithm of income per capita taken from the World Development Indicators of 2010, and index of democracy, the incidence in the current year of an episode of civil war and the cumulative years of peace since the last episode of civil war or independence, and finally, the average prevalence of HIV in neighboring countries.

The main results of DG are presented in Panel A of table 1. Regressions 
with year fixed effects only and with both year and country fixed effects are presented. The positive coefficients associated with oil rents per capita suggest that oil rents are associated with a higher prevalence of HIV (column (1) and (2)), higher death rates from AIDS (columns (3) and (4)) and higher TB prevalence (columns (5) and (6)). In Panel B, the measure of natural resource rents comes from World Bank data on "Adjusted Net Saving". It is an aggregated measure of rents from oil, gas and mineral extraction. Panel C relies on the measure of oil wealth proposed by Cotet and Tsui (2013). Oil wealth is defined as the product of oil price from the BP Statistical Review of World Energy and a measure of oil reserves provided by the Association for the Study of Peak Oil (ASPO). Between 2004 and 2008, oil reserves data comes from BP and Oil and Gas Journal databases. As oil wealth is a stock variable, this measure is less likely to be subject to endogeneity problems. Overall, these regressions suggest that natural resources could fuel the spread of epidemics. This section shows that this result (1) is not robust (2) is spurious because HIV prevalence and oil rents per capita are non-stationary and (3) is impossible to interpret because the expected impact of good policies on HIV prevalence is ambiguous.

\subsection{Non-stationarity of series}

In order to assess the robustness of DG's results to outliers, I repeated their analysis by excluding each country of the sample in turn. Interestingly, only a few countries are responsible for the positive relationship between oil rents per capita and HIV prevalence, namely Sudan, Equatorial Guinea and South Africa. The coefficient associated with oil-rents per capita (log) is greatly reduced and becomes not statistically different from zero when Sudan 


\begin{tabular}{lcccccc}
\hline \hline & \multicolumn{2}{c}{ HIV prevalence $(\log )$} & \multicolumn{2}{c}{ AIDS death rate } & \multicolumn{2}{c}{ TB prevalence (log) } \\
& $(1)$ & $(2)$ & $(3)$ & $(4)$ & $(5)$ & $(6)$ \\
\hline \multicolumn{3}{c}{ Panel A: oil rents data used by de Soysa and Gizelis } & $(2013)$ \\
Rents p.c. $(\log )$ & $0.038^{* * *}$ & $0.062^{* *}$ & $0.040^{* *}$ & 0.042 & $0.036^{* * *}$ & $0.053^{* * *}$ \\
& $(0.013)$ & $(0.030)$ & $(0.019)$ & $(0.036)$ & $(0.012)$ & $(0.015)$ \\
Observations & 2041 & 2041 & 1946 & 1946 & 2022 & 2022
\end{tabular}

Panel B: natural resource rents data from World Bank data on Adjusted Net Saving

$\begin{array}{lcccccc}\text { Rents p.c. }(\log ) & 0.035^{* * *} & 0.059^{* * *} & -0.036^{* *} & -0.023 & 0.050^{* * *} & 0.021^{* * *} \\ & (0.009) & (0.013) & (0.018) & (0.024) & (0.011) & (0.008) \\ \text { Observations } & 1988 & 1988 & 1893 & 1893 & 1969 & 1969\end{array}$

Panel C: oil wealth data (Cotet and Tsui, 2013)

\begin{tabular}{lcccccc} 
Rents p.c. (log) & -0.011 & 0.058 & 0.001 & $0.185^{*}$ & 0.003 & $0.082^{* * *}$ \\
& $(0.010)$ & $(0.054)$ & $(0.014)$ & $(0.097)$ & $(0.009)$ & $(0.031)$ \\
Observations & 1308 & 1308 & 1224 & 1224 & 1289 & 1289 \\
\hline Controls and year FE & Yes & Yes & Yes & Yes & Yes & Yes \\
Country FE & No & Yes & No & Yes & No & Yes \\
\hline \hline
\end{tabular}

Newey-West standard errors in parentheses

${ }^{*} p<0.10,{ }^{* *} p<0.05,{ }^{* * *} p<0.01$

Table 1: Results from de Soysa and Gizelis (2013) for different measures of natural resource rents

or Equatorial Guinea is removed from the sample. If these three countries are jointly removed, the coefficient associated with oil rents per capita becomes negative and statistically different from zero ( $\mathrm{p}$-value $=0.035$ ). Figures 1 (a) to (c) show how HIV prevalence and oil rents per capita have evolved between 1990 and 2008 in the three countries which were shown to drive the findings of DG. It shows that overall, the logarithm of HIV prevalence and the logarithm of oil rents per capita have been increasing between 1990 and 
2008 in these countries. At a first glance, however, the movement of the series does not seem to be synchronized around the increasing "trends". Figures for other countries and other dependent variables follow similar patterns (see online Appendix [INSERT LINK TO ONLINE FILE]).

Taken together, these figures suggest that the positive relationship between HIV prevalence and oil rents per capita may be spurious, driven by the non-stationarity of some of the series. Not taking into account the dynamical structure and the non-stationarity of the series may result in a problem of nonsense or spurious regression (Verbeek, 2008; Baltagi, 2008). Non-stationarity may be induced by the presence of a unit root or by the presence of trends. This distinction is important because the solutions to the non-stationarity problem depend on whether variables of interest are characterized by a unit root or by deterministic trends (Zivot and Wang, 2007; Verbeek, 2008). First differencing is appropriate for time series characterized by a unit root, while time-trend regression is recommended for trend stationary time series. Let us examine these two possibilities in turn.

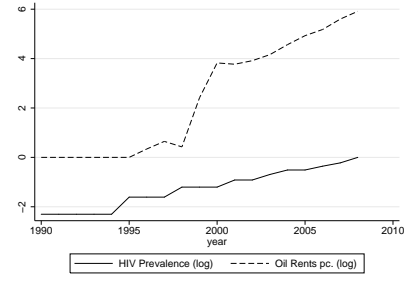

(a) Sudan

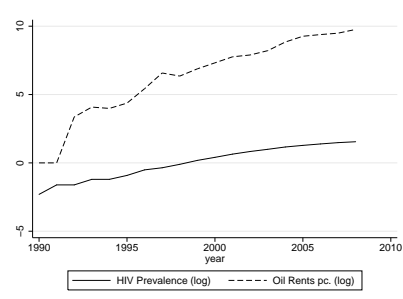

(b) Equatorial Guinea

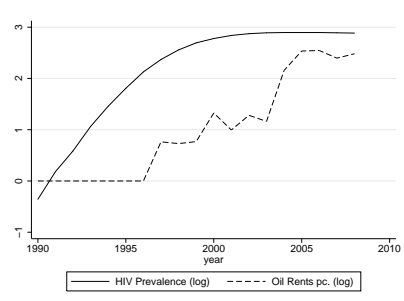

(c) South Africa

Figure 1: Oil rents per capita $(\log )$ and HIV prevalence $(\log )$ between 1990 and 2008

Several tests have been developed in order to assess the presence of 
unit roots in panel data. Here, we focus on the Im-Pesaran-Shin test, the Maddala-Wu test and the Hadri LM test because they allow for heterogeneous auto-regressive coefficients between cross-sectional observations (Verbeek, 2008; Baltagi, 2008). The null hypothesis of the Im-Pesaran-Shin and the Maddala-Wu tests is that all panels have a unit root. On the contrary, the null hypothesis of the Hadri LM test assumes that all country series are stationary. Results of all tests are presented in Appendix [INSERT LINK TO ONLINE FILE]. Importantly, for all dependent variables and all natural resources series, the Hadri LM tests strongly reject the hypothesis that all series are stationary. The Im-Pesaran-Shin and the Maddala-Wu tests suggest that all oil rents and death rates from AIDS series have a unit root. For each cross-sectional unit, I then ran the augmented Dickey-Fuller test (H0 $=$ the variable has a unit root $)$ and the KPSS test $(\mathrm{H} 0=$ the variable has no unit root) in order to identify which country series contain a unit root. Strikingly, a majority of country series seems to be characterized by a unit root.

Recently, stationarity and unit root tests have been extended to take into account structural breaks. However, these tests suffer from problems of size and low power when the time dimension is short, implying that their results have to be interpreted with caution. Applied to our data, the panel stationarity test of Hadri and Rao (2008) fails to reject the null hypothesis of stationarity for all variables. However, the power of this test is extremely low - typically lower than $12 \%$ - when a trend is included in the model and when the time dimension of the panel is low. The problem is similar, although less extreme, for the test of Carrion-i Silvestre et al. (2005). Applied to our case 
study, the test rejects the null hypothesis of stationarity for all variables under the assumption that countries are cross-section independent. This suggests that variables of interest are non-stationary. However, when the assumption of cross-sectional independence is relaxed by computing bootstrap critical values (Maddala and $\mathrm{Wu}, 1999$ ), the null hypothesis fails to be rejected for all but one variable (Log death rates from AIDS). The failure to reject the null hypothesis is most likely due to lack of power. Interestingly, however, tests on country series show that the null hypothesis of stationarity is rejected most of the time, indicating that non-stationarity is likely to be an issue. Similar results are obtained with the Zivot-Andrews unit root test which allows for the presence of structural breaks in the trend and the intercept. A majority of country series seems to be characterized by a unit root.

Even if series have unit roots, a long-term relationship can exist between them if series are cointegrated. Unfortunately, cointegration tests also suffer from serious problems of size and power when the time dimension of the data is limited (see e.g. Haug (1996), Pedroni (2004) or Westerlund (2007)). Therefore, these tests cannot be credibly applied in this case study. Despite these caveats, I carried the Engel-Granger, Westerlund and Pedroni tests, and the results are unsurprising: tests with low power fail to reject the null of no cointegration in all cases; tests with too high size always reject the null. Despite the difficulty to formally test for the presence of a cointegration relationship, several elements indicate that the variables of interest are not cointegrated. First, a simple look at the series suggests that they do not coevolve over time at all (Figures 1 and Figures in Appendix [INSERT LINK TO ONLINE FILE]). Second, and perhaps more importantly, stationarity 
and unit root tests indicate that the order of integration of the dependent and independent variables are different. While HIV prevalence and death rates from AIDS appear to be $\mathrm{I}(2)$, natural resource rents seem to be $\mathrm{I}(1)$ or I(1) with trends. The series are therefore unlikely to be cointegrated.

In the presence of unit roots, a solution often used to avoid the measurement of a nonsense relationship consists in first-differentiating the data until the series are stationary (Verbeek, 2008). Non-stationarity tests show that HIV prevalence and death rates from AIDS need to be first-differentiated twice to be stationary. For TB prevalence and natural resource variables, first-differentiating the variables seems sufficient to obtain series that are trend stationary. In table 2 , the regressions of DG are replicated for firstdifferentiated and second-differentiated series. Country fixed effects disappear with differentiation (results are similar if country fixed effects or countryspecific time trends are included in the regression). Table 2 shows that the relationship between the spread of HIV and TB epidemics and natural resource rents vanishes when series are differentiated.

Non-stationarity can also arise because of the presence of time trends. In order to test for the presence of time trends, I regressed each country series against a time variable and its square. Results are presented in Appendix [INSERT LINK TO ONLINE FILE] for each dependent variable and each natural resource indicator. These regressions show that a large majority of country series are characterized by non-linear trends. Importantly, the coefficients associated with the time variables are significantly different from one country to another. The fact that the series of interest have time trends 
implies that the fixed effect estimator is likely to give spurious results. The introduction of year fixed effects is not expected to prevent the spurious regression phenomenon as the time trends characterizing series are different from one country to another. To prevent spurious inference, country-specific quadratic time trends have to be included in the regression. According to the Frisch-Waugh-Lovel theorem, the introduction of a time trend in the regression is equivalent to running the regression with detrended variables (Baltagi, 2011). As shown in columns (3), (6) and (9) of table 2, the relationship between HIV prevalence and oil rents per capita vanishes when quadratic time trends are included in the regression. Similar conclusions are reached for death rates from AIDS and TB prevalence.

Results from table 2 show that the identification of a resource curse on HIV is likely to be spurious. In line with the resource curse literature, I further tested whether the relationship between the spread of epidemics and natural resource could depend on other variables like governance, human capital or migration. For example, one could imagine that natural resources could hinder effective action against HIV in corrupted countries. Or on the contrary, natural resource rents could help financing sound policies against HIV in least corrupt country. To test these hypotheses, interaction terms were introduced in the different models of table 2. The following moderator variables were considered: the Cheibub et al. (2010) index of democracy, the control of corruption index and law and order index from ICRG (2006) and GDP per capita, education spending (per capita and in \% of GNI) and immigration rates from the 2010 World Development Indicators. Results are presented in Appendix [INSERT LINK TO ONLINE FILE]. Overall, there 
is no robust evidence that these variables condition the impact of natural resources on the spread of HIV and TB epidemics.

\subsection{The ambiguous impact of prevention and treatment on dependent vari- ables}

DG justify the presence of a resource curse on HIV by the fact that "rulers in resource-wealthy states are more likely to neglect public goods provision, such as health, and neglect effective public action". In their main specification, the dependent variable is the logarithm of the prevalence. However, the choice of HIV prevalence as a dependent variable is misleading because the impact of good/bad policies on prevalence is ambiguous.

The optimal response to the HIV/AIDS epidemic is a mix of prevention and ART. Prevention is expected to reduce HIV incidence and HIV prevalence. The impact of treatment is both to increase life expectancy and to reduce infectiousness. In the short and medium run, ART should increase prevalence through increased life expectancy. In the long run, however, prevalence should be reduced because of the reduced infectiousness of HIV-positive individuals on ART. The total impact of an effective public response to the HIV epidemic on HIV prevalence is therefore ambiguous in the short and medium run. A positive correlation between oil rents per capita and HIV prevalence can be interpreted as a neglect of public goods provision, but also as a consequence of increased access to HIV treatment.

Furthermore, the fact that HIV prevalence is a stock while natural resource rents are a flow has implications on long-run dynamics. Even if a country implements sound public policies, its HIV prevalence can be high 
Table 2: First- and second-difference models and quadratic trends

\begin{tabular}{|c|c|c|c|c|c|c|c|c|c|}
\hline & \multicolumn{3}{|c|}{ Oil rents data - WB } & \multicolumn{3}{|c|}{ Total rents data - WB } & \multicolumn{3}{|c|}{ Oil wealth - ASPO } \\
\hline & $\Delta$ & $\Delta^{2}$ & $\begin{array}{c}\text { Quadratic } \\
\text { trend }\end{array}$ & $\Delta$ & $\Delta^{2}$ & $\begin{array}{c}\text { Quadratic } \\
\text { trend }\end{array}$ & $\Delta$ & $\Delta^{2}$ & $\begin{array}{c}\text { Quadratic } \\
\text { trend }\end{array}$ \\
\hline & (1) & $(2)$ & $(3)$ & $(4)$ & (5) & (6) & $(7)$ & (8) & (9) \\
\hline \multicolumn{10}{|c|}{ Panel A - dependent variable: HIV prevalence (log) } \\
\hline \multirow[t]{2}{*}{ Rents p.c. $(\log )$} & 0.015 & -0.015 & 0.027 & 0.001 & -0.008 & -0.009 & -0.006 & -0.016 & $-0.053^{* * *}$ \\
\hline & $(0.011)$ & $(0.023)$ & $(0.021)$ & $(0.003)$ & $(0.008)$ & $(0.009)$ & $(0.012)$ & $(0.011)$ & $(0.019)$ \\
\hline Observations & 1902 & 1790 & 2041 & 1850 & 1740 & 1988 & 1227 & 1146 & 1308 \\
\hline \multicolumn{10}{|c|}{ Panel B - dependent variable: death rates from AIDS (log) } \\
\hline \multirow[t]{2}{*}{ Rents p.c. $(\log )$} & 0.017 & 0.027 & 0.032 & -0.009 & 0.001 & $-0.063^{* * *}$ & 0.026 & 0.005 & 0.045 \\
\hline & $(0.019)$ & $(0.021)$ & $(0.028)$ & $(0.012)$ & $(0.012)$ & $(0.018)$ & $(0.017)$ & $(0.019)$ & $(0.034)$ \\
\hline Observations & 1812 & 1705 & 1946 & 1760 & 1655 & 1893 & 1148 & 1072 & 1224 \\
\hline \multicolumn{10}{|c|}{ Panel $C$ - dependent variable: TB prevalence (log) } \\
\hline \multirow[t]{2}{*}{ Rents p.c. $(\log )$} & -0.007 & -0.024 & 0.005 & 0.008 & 0.002 & 0.005 & 0.006 & -0.003 & 0.002 \\
\hline & $(0.017)$ & $(0.032)$ & $(0.014)$ & $(0.007)$ & $(0.007)$ & $(0.006)$ & $(0.008)$ & $(0.009)$ & $(0.011)$ \\
\hline Observations & 1884 & 1773 & 2022 & 1832 & 1723 & 1969 & 1209 & 1129 & 1289 \\
\hline \multicolumn{10}{|c|}{ Panel D - dependent variable: HIV incidence (log) } \\
\hline \multirow[t]{2}{*}{ Rents p.c. $(\log )$} & $0.005^{*}$ & 0.001 & 0.004 & 0.001 & 0.001 & $0.003^{*}$ & 0.003 & 0.000 & -0.002 \\
\hline & $(0.003)$ & $(0.002)$ & $(0.005)$ & $(0.001)$ & $(0.001)$ & $(0.002)$ & $(0.002)$ & $(0.001)$ & $(0.005)$ \\
\hline Observations & 1902 & 1790 & 2041 & 1850 & 1740 & 1988 & 1227 & 1146 & 1308 \\
\hline \multicolumn{10}{|c|}{ Panel E - dependent variable: HIV incidence (log), controlling for HIV prevalence and its square } \\
\hline \multirow[t]{2}{*}{ Rents p.c. $(\log )$} & 0.004 & 0.000 & 0.000 & 0.001 & 0.001 & $0.003^{*}$ & 0.002 & 0.001 & 0.003 \\
\hline & $(0.002)$ & $(0.002)$ & $(0.004)$ & $(0.001)$ & $(0.001)$ & $(0.001)$ & $(0.002)$ & $(0.001)$ & $(0.005)$ \\
\hline \multirow[t]{2}{*}{ HIV prevalence (log) } & $0.120^{* * *}$ & $0.066^{* *}$ & $0.170^{* * *}$ & $0.109^{* * *}$ & $0.063^{* *}$ & $0.151^{* * *}$ & $0.123^{* * *}$ & $0.071^{* *}$ & $0.135^{* * *}$ \\
\hline & $(0.019)$ & $(0.026)$ & $(0.032)$ & $(0.020)$ & $(0.027)$ & $(0.033)$ & $(0.025)$ & $(0.034)$ & $(0.045)$ \\
\hline \multirow[t]{2}{*}{ HIV prevalence ${ }^{2}(\log )$} & $0.027^{* * *}$ & $0.018^{* *}$ & $0.034^{* * *}$ & $0.024^{* * *}$ & $0.017^{* *}$ & $0.028^{* * *}$ & $0.028^{* * *}$ & $0.018^{*}$ & $0.027^{* *}$ \\
\hline & $(0.006)$ & $(0.007)$ & $(0.009)$ & $(0.006)$ & $(0.007)$ & $(0.009)$ & $(0.007)$ & $(0.009)$ & $(0.012)$ \\
\hline Observations & 1902 & 1790 & 2041 & 1850 & 1740 & 1988 & 1227 & 1146 & 1308 \\
\hline Controls and year FE & Yes & Yes & Yes & Yes & Yes & Yes & Yes & Yes & Yes \\
\hline Country FE & No & No & Yes & No & No & Yes & No & No & Yes \\
\hline
\end{tabular}


because of past negligence. HIV prevention is expected to have a long-run impact on HIV prevalence by affecting behavior in the long run and by reducing the pool of infected and infectious individuals. Regressing HIV prevalence, which is a stock, on a flow measure of oil production is therefore problematic as it will fail to control for these long-run dynamics.

The expected impacts of sound public policies on death rates from AIDS and TB prevalence are less ambiguous than for HIV prevalence. Both prevention and treatment should reduce the death rate from AIDS. First-line treatment against TB is of shorter duration than long-life HIV treatments, implying that both prevention and treatment against TB should reduce TB prevalence. However, as for HIV prevalence, prevention is expected to have a long-run impact on death rates from AIDS and on TB prevalence. The median time from HIV infection to AIDS death without ART is about 11.2 years (Todd et al., 2007). Therefore, it is only years later that one HIV infection adverted will be reflected in death rates from AIDS. These dynamics are not accounted for in the specification of DG.

HIV incidence is less likely to be affected by these problems. Both prevention and ART treatment should reduce HIV incidence. The link between sound public policies and HIV incidence is expected to be measurable in the short-run. According to stationarity and unit root tests, HIV incidence needs to be differentiated twice to become stationary. Most country series are characterized by a quadratic trend. In panel D of 2 , the regressions in first- and second-differences and the regressions with quadratic trends are replicated for HIV incidence. There is no robust evidence of a resource curse on HIV. 
Of course, past policies can also have a long-lasting impact on HIV incidence both because prevention can have long-run effects on behavior and because HIV incidence is highly correlated with HIV prevalence in accordance with epidemiological models (Keeling and Rohani, 2008). In panel E of 2, HIV prevalence and its square are included as control variable, without significantly affecting the results. As expected, HIV prevalence and its square are highly significant in all regressions.

\section{Taking a long-run perspective}

\subsection{Identification strategy}

The analysis of the previous section showed that a rigorous assessment of the relationship between natural resource abundance and the spread of the HIV epidemic should: (1) be based on indicators that are not ambiguous, (2) account for the epidemiology of the HIV epidemic and capture the long-run impact of prevention and treatment on its spread, and finally (3) be based on a rigorous method which is not subject to the problem of spurious regression and does not remove all the variation in HIV series. This section proposes an alternative specification which aims to solve these challenges in a single move.

The method proposed is inspired from the work of Alexeev and Conrad (2009). These authors criticized the usual approach to testing the presence of the curse of oil which consists of regressing GDP growth rates over a period of time on a measure of the economy's reliance on oil and on other control variables. Because more or less reliable GDP data is only available from 1970 onwards, this method does not take into account the fact that 
resource-rich countries may have grown on average more than their resourcepoor counterparts, but that this higher growth rate occurred before 1970 . Following Hall and Jones (1999), Easterly and Levine (2003) and Rodrik et al. (2004), they consider levels of GDP per capita rather than growth rates. As they argue: "After all, countries with high per capita GDP must have been growing fast at some point in time".

In line with this, three different dependent variables will be used in this section: the total number of people ever infected by the HIV virus, the total number of people who died from AIDS and the total number of people who developed TB since 1990. These indicators are constructed as follows. First, the total number of individuals which were infected by the HIV virus is simply the sum of HIV incidence between 1990 and 2008, plus the prevalence in 1990. The second indicator is the sum of death rates from AIDS since 1990. The last indicator is the aggregated TB prevalence since 1990. Contrary to HIV prevalence, these new indicators are expected to be negatively affected by both prevention and treatment.

Three "stock" measures of natural resource wealth will be used as independent variable. The first two series are the sum of natural resource rents per capita in constant \$US over 1990-2008, using DG data and World Bank data on "Adjusted Net Saving" respectively. The third measure is based on oil wealth data from Cotet and Tsui (2013). As oil wealth is already a stock variable, I consider the average of oil wealth between 1990 and 2008. Using the value of natural resource in 1990 does not alter significantly the results. In order to obtain comparable results, the set of control variables 
is based on the DG analysis. The value of the variables in 1990 is used in order to minimize the risk of endogeneity. In line with Oster (2012), I also included the distance to the origin of the HIV virus, its square and its cube as supplementary control variables.

Two estimation strategies were implemented. First, I ran simple crosssectional regressions with the full sample of countries. However, this estimation method is known to be sensitive to the omitted-variable bias as it compares countries that are different in many dimensions. The second method aims at minimizing this risk by imposing "tight fixed effect" (Colombo et al., 2014). The idea is to build a new dataset identifying each pair of neighboring countries with a dummy variable. Including these dummies into the regression as fixed effects allows to compare countries only with their closest neighbors. Except from their natural resource endowments which can be seen as quasi-random (Collier, 2010), close neighbors are expected to be very similar, thereby minimizing the risk of omitted-variables bias. As countries may have several neighbors and may be the neighbors of several countries, some lines will be duplicated in this new dataset. Standard errors are therefore clustered at three levels (Cameron et al., 2011; Colombo et al., 2014).

It should be emphasized that these estimation strategies are not subject to the problem of non-stationarity and are expected to preserve some of the variability necessary to measure any significant effect. For these reasons, the proposed strategies seem more prudent than methods using the panel dimension of the data. 


\subsection{Results}

The results of OLS estimates are presented in table 3. The proxies for natural resource wealth are the total oil rents per capita in columns (1) and (2), the total natural resource rents from the World Bank database in columns (3) and (4) and the average of oil wealth from Cotet and Tsui (2013) in columns (5) and (6). Cross-sectional regressions are presented in columns (1), (3) and (5). The results of the "tight fixed effects" method are shown in columns (2), (4) and (6).

In Panel A, the dependent variable is aggregated measure of HIV incidence $(\log )$. The coefficients associated with oil wealth are negative and not significant. Overall, the results are consistent with the absence of a resource curse on HIV/AIDS. Similar results are obtained when the dependent variable is the total number of death from AIDS (panel B) or the aggregated TB prevalence (panel C).

Among control variables, results show that the incidence of a civil conflict in 1990 seems to have a weakly significant negative impact on the the spread of HIV. This may be explained by the fact that civil conflicts reduce overall the possibilities of engaging in risky sexual behavior, and this, despite too frequent abuses committed during conflict situations. In line with the literature, I find that poverty is an important driver of the spread of TB (e.g. Burke et al. (2014) or Oxlade and Murray (2012)).

These results are robust to alternative specifications. I included interaction variables between natural resource wealth per capita and indexes of democracy, control of corruption, law and order, GDP per capita, education 
Table 3: The long-run impact of natural resources on the spread of epidemics

\begin{tabular}{|c|c|c|c|c|c|c|}
\hline & \multicolumn{2}{|c|}{$\begin{array}{l}\text { Aggregated } \\
\text { oil rents }\end{array}$} & \multicolumn{2}{|c|}{$\begin{array}{l}\text { Aggregated } \\
\text { total rents }\end{array}$} & \multicolumn{2}{|c|}{$\begin{array}{c}\text { Average } \\
\text { Oil wealth }\end{array}$} \\
\hline & (1) & $(2)$ & $(3)$ & $(4)$ & $(5)$ & $(6)$ \\
\hline \multicolumn{7}{|c|}{ Panel $A$ - dependent variable: aggregated measure of HIV incidence (log) } \\
\hline \multirow[t]{2}{*}{ Aggregated rents p.c. (log) } & -0.012 & -0.006 & -0.010 & -0.106 & -0.086 & -0.070 \\
\hline & $(0.033)$ & $(0.028)$ & $(0.035)$ & $(0.070)$ & $(0.107)$ & $(0.084)$ \\
\hline Observations & 87 & 324 & 87 & 324 & 66 & 216 \\
\hline \multicolumn{7}{|c|}{ Panel B - dependent variable: aggregated measure of death rates from AIDS (log) } \\
\hline \multirow[t]{2}{*}{ Aggregated rents p.c. (log) } & -0.025 & -0.001 & -0.086 & -0.019 & -0.020 & 0.093 \\
\hline & $(0.044)$ & $(0.062)$ & $(0.079)$ & $(0.164)$ & $(0.122)$ & $(0.113)$ \\
\hline Observations & 82 & 276 & 82 & 276 & 61 & 176 \\
\hline \multicolumn{7}{|c|}{ Panel $C$ - dependent variable: aggregated TB prevalence (log) } \\
\hline \multirow[t]{2}{*}{ Aggregated rents p.c. $(\log )$} & 0.007 & 0.019 & 0.036 & 0.064 & -0.043 & -0.024 \\
\hline & $(0.029)$ & $(0.026)$ & $(0.045)$ & $(0.079)$ & $(0.089)$ & $(0.102)$ \\
\hline Observations & 86 & 316 & 86 & 316 & 65 & 212 \\
\hline Controls & Yes & Yes & Yes & Yes & Yes & Yes \\
\hline Pair FE & No & Yes & No & Yes & No & Yes \\
\hline
\end{tabular}

spending or immigration rates. No robust results emerge when interaction terms are included in the regression. Considering only African countries or using the between-estimator with the panel data gives similar results. The latter method is not subject to the problem of non-stationarity. 


\section{The potential of natural resource rents to finance the response against HIV/AIDS}

In the previous section, we have seen that natural resources have not yet had a significant impact on the spread of the HIV/AIDS epidemic. Indeed, before the large scaling-up of antiretroviral therapies in developing countries, the spread of HIV/AIDS has mainly been driven by epidemiological and behavioral factors. This does not mean that natural resources will not have an important role to play in the future. Indeed, the fiscal space which may be potentially created via an efficient exploitation of natural resources offers a real opportunity for resource-rich countries to finance their long-term response to the HIV/AIDS epidemic. This section discusses this opportunity in the context of sub-Saharan Africa, with a focus on the long-run cost of ART.

In a context of increasing access to cheap antiretroviral drugs, more and more developing countries have committed to universal access to ART. Despite these good intentions, ART coverage in sub-Saharan Africa is mixed, ranging from 1\% in Madagascar to more than $90 \%$ in Botswana, Cape Verde and Namibia according to 2012 UNAIDS estimates. Funds are of course necessary for financing universal access to ART treatment (Collier et al., 2015). The cost per capita of universal access to ART is estimated for each subSaharan African country in table 4 for the year 2011. For each country, I used the Spectrum software to compute the number of people needing ART in 2011 (CD4 $\leq 350$ cells $/ \mathrm{mm}^{3}$ ). This estimate was the multiplied by the median yearly cost of ART taken from Galárraga and Wirtz (2011) and divided by the population size of the country (World Development Indicators). 
The cost per capita of universal access to ART varies a lot across countries. It is typically lower than 5 US\$ per capita in low-prevalence countries and in countries whose epidemic is at an early stage. In high-prevalence countries, the cost is much higher, reaching 89 US\$ in Swaziland and 143 US\$ in Botswana. As HIV positive individuals need to be treated for their whole life, it is worth noting that the cost of universal ART coverage is expected to increase in the short and medium run.

Given the recent flat trend characterizing international funding for HIV/AIDS, sub-Saharan African countries will have to increase their own contribution to fulfill the objective of universal ART coverage. Within this context, natural resource rents may be a credible solution for creating fiscal space. This possibility has not been considered in recent studies assessing how fiscal space could be created to increase domestic financing of HIV programs (Resch et al., 2015; Galárraga et al., 2013). For each country, table 4 reports the cost of universal access to ART as a fraction of GDP and as a fraction of natural resource rents. Countries are classified in 3 groups, according to their relative capacity to create fiscal space.

The first group of countries includes Central African Republic, Mozambique, Malawi, Namibia, Zimbabwe, Swaziland and Lesotho. In these countries, the prevalence of HIV is so high compared to their GDP that the cost of universal ART coverage represents more than 1\% of their GDP and more than $20 \%$ of their natural resource rents. Given this high cost, natural resource rents are not expected to be sufficient for financing the response to $\mathrm{HIV} / \mathrm{AIDS}$ in these countries. If ART is scaled-up, international aid will 
most likely have to cover a large part of cost.

For a second group of countries comprising Guinea-Bissau, Togo, Uganda, Rwanda, Botswana and Kenya, the diagnosis is slightly more encouraging. The burden of the HIV/AIDS epidemic is relatively important in these countries, implying that the cost of universal ART coverage is non-negligible compared to size of their economy. These countries would typically have to dedicate between $0.5 \%$ and $1 \%$ of their GDP in order to finance alone the universal coverage of ART. For them, natural resource rents may provide a realistic but limited source of financing: more than $10 \%$ of their natural resource rents would have to be allocated to ART to cover the full cost of universal ART coverage.

For the last group, accounting for more than half of sub-Saharan African countries, the diagnostic which can be established from table 4 is promising. In these countries, the cost of universal ART coverage represents less than $10 \%$ of natural resource rents, which suggests that a sustainable and efficient management or natural resource rents may provide the necessary fiscal resources for financing their long-term response to the HIV/AIDS epidemic.

Three qualifying remarks should be made to temper this conclusion. First, as the majority of high-prevalence countries are poor, and given the numerous needs brought about by poverty, rents from natural resources will most likely not be entirely affected to the response to HIV/AIDS. Tax collection in many of these countries remains challenging. Given these difficulties, international aid for HIV/AIDS will remain essential, at least in the medium run. Second, and in line with the paper of de Soysa and Gizelis (2013), natural re- 
source rents will only have a positive impact on the response to HIV/AIDS if these rents are managed with an appropriate degree of care and control, and within an appropriate framework of ethics and values. For this purpose, recent initiatives such as the "Natural Resource Charter" may provide essential guidelines for countries to get full benefit from their natural resources and ultimately secure the greatest social and economic benefit for their people. Finally, the link between natural resource rents and international aid may be complex, and may potentially affect the fiscal space available of HIV/AIDS programs. On the one side, the presence of large natural resource rents may reduce international aid earmarked to HIV/AIDS if donor countries prefer to redirect their funds towards countries less fortunate in terms of natural capital. On the other side, the possession of strategic resources may increase the bargaining power of resource-rich countries and thereby increases the amount of international aid they receive. More empirical research is needed to understand the complex links between international assistance and natural resource rents.

\section{Conclusion}

Using a panel dataset of countries between 1990 and 2008, de Soysa and Gizelis (2013) provided evidence that oil-rich countries are more deeply affected by HIV and TB. This paper showed that their results are not robust, driven by the non-stationarity of series and impossible to interpret. After correcting for these issues, this paper found no robust evidence of a strong relationship between natural resources and the spread of these epidemics.

This study is subject to a number of limitations which relate to data avail- 
Table 4: natural resource rents and HIV in sub-Saharan Africa

\begin{tabular}{|c|c|c|c|c|c|c|}
\hline & \multirow{2}{*}{$\begin{array}{c}\text { HIV prevalence } \\
\text { ages } 15-49 \\
\text { (percent) }\end{array}$} & \multirow{2}{*}{$\begin{array}{c}\text { GDP per } \\
\text { capita } \\
\text { (US\$, 2011) }\end{array}$} & \multirow{2}{*}{$\begin{array}{l}\text { Natural resources } \\
\text { rents per capita } \\
\text { (US\$, 2011) }\end{array}$} & \multicolumn{3}{|c|}{ Cost per capita of universal access to ART in 2011} \\
\hline & & & & (US\$, 2011) & $\begin{array}{l}\text { (\% of GDP } \\
\text { per capita) }\end{array}$ & $\begin{array}{l}\text { (\% of rents } \\
\text { per capita) }\end{array}$ \\
\hline Mauritius & 1.2 & 14,881 & 1 & 4 & $0.0 \%$ & $447.9 \%$ \\
\hline Lesotho $* *$ & 23.1 & 1,865 & 24 & 79 & $4.3 \%$ & $332.7 \%$ \\
\hline Swaziland ** & 26.5 & 5,284 & 85 & 89 & $1.7 \%$ & $104.5 \%$ \\
\hline Zimbabwe $* *$ & 14.7 & 524 & 36 & 33 & $6.2 \%$ & $90.6 \%$ \\
\hline Namibia $* *$ & 13.3 & 7,170 & 102 & 69 & $1.0 \%$ & $67.6 \%$ \\
\hline Malawi ** & 10.8 & 890 & 35 & 22 & $2.5 \%$ & $63.3 \%$ \\
\hline Kenya * & 6.1 & 1,695 & 24 & 13 & $0.8 \%$ & $53.9 \%$ \\
\hline Eritrea & 0.7 & 534 & 3 & 2 & $0.3 \%$ & $51.7 \%$ \\
\hline Mozambique ** & 11.1 & 955 & 69 & 19 & $2.0 \%$ & $27.3 \%$ \\
\hline Sao Tome and Principe & 1 & 1,787 & 16 & 4 & $0.2 \%$ & $23.7 \%$ \\
\hline Central African Republic $* *$ & 4.4 & 820 & 42 & 9 & $1.1 \%$ & $22.1 \%$ \\
\hline Botswana * & 23 & 15,509 & 723 & 143 & $0.9 \%$ & $19.8 \%$ \\
\hline Rwanda * & 2.9 & 1,260 & 41 & 8 & $0.6 \%$ & $18.9 \%$ \\
\hline Uganda * & 7.2 & 1,320 & 71 & 11 & $0.9 \%$ & $16.1 \%$ \\
\hline Togo $*$ & 2.9 & 998 & 48 & 6 & $0.6 \%$ & $13.3 \%$ \\
\hline Guinea-Bissau * & 3.9 & 1,211 & 56 & 6 & $0.5 \%$ & $11.1 \%$ \\
\hline Benin & 1.1 & 1,508 & 25 & 3 & $0.2 \%$ & $10.3 \%$ \\
\hline Cote d'Ivoire & 3.2 & 1,862 & 144 & 12 & $0.6 \%$ & $8.0 \%$ \\
\hline Tanzania & 5.1 & 1,508 & 126 & 10 & $0.6 \%$ & $7.7 \%$ \\
\hline Niger & 0.5 & 607 & 15 & 1 & $0.2 \%$ & $6.5 \%$ \\
\hline Zambia & 12.7 & 1,609 & 434 & 28 & $1.7 \%$ & $6.4 \%$ \\
\hline Sierra Leone & 1.5 & 1,174 & 42 & 3 & $0.2 \%$ & $6.3 \%$ \\
\hline Cameroon & 4.5 & 2,241 & 221 & 13 & $0.6 \%$ & $6.0 \%$ \\
\hline Ethiopia & 1.3 & 1,052 & 63 & 4 & $0.3 \%$ & $5.8 \%$ \\
\hline South Africa & 17.9 & 11,028 & 1,173 & 66 & $0.6 \%$ & $5.6 \%$ \\
\hline Burundi & 1.3 & 543 & 56 & 3 & $0.6 \%$ & $5.6 \%$ \\
\hline Gambia, The & 1.3 & 1,853 & 43 & 2 & $0.1 \%$ & $4.8 \%$ \\
\hline Liberia & 0.9 & 593 & 65 & 2 & $0.4 \%$ & $3.4 \%$ \\
\hline Senegal & 0.5 & 1,886 & 64 & 2 & $0.1 \%$ & $2.9 \%$ \\
\hline Ghana & 1.4 & 1,894 & 271 & 5 & $0.3 \%$ & $1.8 \%$ \\
\hline Burkina Faso & 1 & 1,382 & 163 & 2 & $0.2 \%$ & $1.5 \%$ \\
\hline Guinea & 1.7 & 1,031 & 208 & 3 & $0.3 \%$ & $1.4 \%$ \\
\hline Madagascar & 0.5 & 953 & 54 & 1 & $0.1 \%$ & $1.4 \%$ \\
\hline Congo, Dem. Rep. & 1.1 & 396 & 139 & 2 & $0.5 \%$ & $1.4 \%$ \\
\hline Mali & 0.9 & 1,237 & 176 & 2 & $0.2 \%$ & $1.2 \%$ \\
\hline Nigeria & 3.1 & 2,509 & 897 & 9 & $0.4 \%$ & $1.0 \%$ \\
\hline Chad & 2.7 & 1,431 & 549 & 5 & $0.4 \%$ & $0.9 \%$ \\
\hline Comoros & 2.1 & 1,196 & 14 & 0 & $0.0 \%$ & $0.5 \%$ \\
\hline Congo, Rep. & 2.8 & 4,276 & 3,150 & 10 & $0.2 \%$ & $0.3 \%$ \\
\hline Gabon & 4 & 15,169 & 7,671 & 20 & $0.1 \%$ & $0.3 \%$ \\
\hline Angola & 2.3 & 5,760 & 2,682 & 6 & $0.1 \%$ & $0.2 \%$ \\
\hline Equatorial Guinea & 6.2 & 29,631 & 12,265 & 20 & $0.1 \%$ & $0.2 \%$ \\
\hline
\end{tabular}


ability and quality. The short time dimension of the panel dataset $(\mathrm{T}=19)$ implies that most stationarity, unit root and cointegration tests suffer from serious problems of size and power. This explains why different tests may reach conflicting conclusions. HIV and TB series are estimated on the basis of epidemiological models and are hence subject to measurement errors (UNAIDS, 2013b). While measurement problems are expected to increase standard errors, they are unlikely to bias the estimates because HIV and TB series are used as left-hand side variables (Hausman, 2001). With these limitations in mind, it is difficult to draw a firm conclusion on the existence or absence of a relationship between natural resources and the spread of epidemics. I conclude that if a relationship between natural resources and the spread of epidemics exists, it is likely to be weak.

The main contributions of this paper are the following. First, it shows that the results of de Soysa and Gizelis (2013) are not robust. More generally, this paper demonstrates the difficulty of panel data analysis with epidemiological data and short panel. It provides some tools to produce a rigorous analysis. Finally, it shows that in a majority of sub-Saharan African countries, natural resources offer a considerable potential to create fiscal space. This fiscal space may then be critical to finance the long-term liability brought about by the scaling-up of antiretroviral therapies.

\section{References}

Alexeev, M. and R. Conrad (2009). The elusive curse of oil. The Review of Economics and Statistics 91 (3), 586-598. 
Baltagi, B. H. (2008). Econometric analysis of panel data. John Wiley and Sons.

Baltagi, B. H. (2011). Econometrics. Springer Texts in Business and Economics. Springer.

Burke, S. J., E. Lass, P. Thistle, L. Katumbe, A. Jetha, D. Schwarz, S. Bolotin, R. Barker, A. Simor, and M. Silverman (2014). Increased incidence of tuberculosis in zimbabwe, in association with food insecurity, and economic collapse: An ecological analysis. PLoS one 9(2), e83387.

Cameron, C., J. Gelbach, and D. Miller (2011, April). Robust inference with multiway clustering. Journal of Business \&6 Economic Statistics 29(2), $238-249$.

Carrion-i Silvestre, J. L., D. Barrio-Castro, and E. López-Bazo (2005). Breaking the panels: an application to the GDP per capita. The Econometrics Journal 8(2), 159-175.

Cheibub, J. A., J. Gandhi, and J. R. Vreeland (2010). Democracy and dictatorship revisited. Public Choice 143(1-2), 67-101.

Collier, P. (2010). The Plundered Planet: Why We Must-and How We CanManage Nature for Global Prosperity. Oxford University Press.

Collier, P., O. Sterck, R. Manning, et al. (2015). The moral and fiscal implications of antiretroviral therapies for HIV in Africa. CSAE Working Paper 2015-05. 
Colombo, A., O. D'Aoust, and O. Sterck (2014). From rebellion to electoral violence evidence from Burundi. ECARES Working Papers 2014-33.

Cotet, A. M. and K. K. Tsui (2013). Oil and conflict: what does the cross country evidence really show? American Economic Journal: Macroeconomics 5(1), 49-80.

de Soysa, I. and T.-I. Gizelis (2013). The natural resource curse and the spread of HIV/AIDS, 1990-2008. Social Science \& Medicine 77(C), 9096.

Easterly, W. and R. Levine (2003). Tropics, germs, and crops: how endowments influence economic development. Journal of Monetary Economics $50(1), 3-39$.

Galárraga, O. and V. Wirtz (2011). Unit costs for delivery of antiretroviral treatment and prevention of mother-to-child transmission of HIV. Pharmacoeconomics 29(7), 1-27.

Galárraga, O., V. J. Wirtz, Y. Santa-Ana-Tellez, and E. L. Korenromp (2013). Financing HIV programming: how much should low-and middleincome countries and their donors pay? PLoS one 8(7), e67565.

Hadri, K. and Y. Rao (2008). Panel stationarity test with structural breaks. Oxford Bulletin of Economics and Statistics 70(2), 245-269.

Hall, R. E. and C. I. Jones (1999). Why do some countries produce so much more output per worker than others? The Quarterly Journal of Economics 114(1), 83-116. 
Haug, A. A. (1996). Tests for cointegration a monte carlo comparison. Journal of Econometrics 71(1), 89-115.

Hausman, J. (2001). Mismeasured variables in econometric analysis: problems from the right and problems from the left. Journal of Economic Perspectives 15(4), 57-67.

ICRG (2006). Icrg researcher data. The Political Risk Services Group.

Keeling, M. J. and P. Rohani (2008). Modeling infectious diseases in humans and animals. Princeton University Press.

Maddala, G. S. and S. Wu (1999). A comparative study of unit root tests with panel data and a new simple test. Oxford Bulletin of Economics and Statistics 61(S1), 631-652.

Oster, E. (2012). HIV and sexual behavior change: why not Africa? Journal of Health Economics 31(1), 35-49.

Oxlade, O. and M. Murray (2012). Tuberculosis and poverty: why are the poor at greater risk in India? PLoS one 7(11), e47533.

Pedroni, P. (2004). Panel cointegration: asymptotic and finite sample properties of pooled time series tests with an application to the PPP hypothesis. Econometric Theory 20(03), 597-625.

Resch, S., T. Ryckman, and R. Hecht (2015). Funding AIDS programmes in the era of shared responsibility: an analysis of domestic spending in 12 low-income and middle-income countries. The Lancet Global Health 3(1), e52-e61. 
Rodrik, D., A. Subramanian, and F. Trebbi (2004). Institutions rule: the primacy of institutions over geography and integration in economic development. Journal of Economic Growth 9(2), 131-165.

Todd, J., J. R. Glynn, M. Marston, T. Lutalo, S. Biraro, W. Mwita, V. Suriyanon, R. Rangsin, K. E. Nelson, P. Sonnenberg, et al. (2007). Time from HIV seroconversion to death: a collaborative analysis of eight studies in six low and middle-income countries before highly active antiretroviral therapy. AIDS 21, S55-S63.

UNAIDS (2013a). Global report: UNAIDS report on the global AIDS epidemic 2013. UNAIDS Geneva.

UNAIDS (2013b). Methodology $\hat{a} \breve{A S}$ Understanding the HIV estimates. UNAIDS Geneva.

van der Ploeg, F. (2011). Natural resources: curse or blessing? Journal of Economic Literature 49(2), 366-420.

Verbeek, M. (2008). A guide to modern econometrics. John Wiley and Sons.

Westerlund, J. (2007). Testing for error correction in panel data. Oxford Bulletin of Economics and Statistics 69(6), 709-748.

Zivot, E. and J. Wang (2007). Modeling Financial Time Series with S-PLUS, Volume 191. Springer Science \& Business Media. 